\title{
CORRECTED PROOF
}

\section{Copyright $\odot$ The British Psychological Society}

Reproduction in any form (including the internet) is prohibited without prior permission from the Society

\section{Psychological processing of transplantation in lung recipients: A quantitative study of organ integration and the relationship to the donor}

\author{
Lutz Goetzmann ${ }^{\prime *}$, Sarosh Irani ${ }^{2}$, Karin S. Moser ${ }^{3}$, \\ Kyrill Schwegler', Martina Stamm', Anja Spindler', \\ Claus Buddeberg ${ }^{1}$, Christoph Schmid ${ }^{2}$, Annette Boehler ${ }^{2}$ \\ and Richard Klaghofer' \\ 'Psychosocial Medicine, University Hospital Zurich, Zurich, Switzerland \\ ${ }^{2}$ Pulmonary Medicine and Lung Transplant Programme, University Hospital Zurich, \\ Zurich, Switzerland \\ ${ }^{3}$ Department of Social Psychology, Roehampton University, London, UK
}

\begin{abstract}
Objectives. Lung recipients undergo a complex psychological process, including organ integration and processing of attitudes towards the organ donor.

Design. Seventy-six lung recipients were asked to participate in a cross-sectional questionnaire study on the psychological processing of lung transplants.

Methods. The questionnaire consisted of statements describing aspects of organ integration and the patient's relationship with the donor. Furthermore, chronic stress/psychological distress (Screening Scale of the Trier Inventory; Symptom Checklist SCL-K-9) and the emotional effects of transplantation/immunosuppression (Transplant Effects Questionnaire; Medication Experience Scale for Immunosuppressants) were assessed.
\end{abstract}

Results. In general, lung recipients perceive the transplant as part of themselves (97.4\%) and not as a foreign object (90\%). One-third of patients still have frequent thoughts about the donor, whilst the majority (80.3\%) do not believe that they have adopted the donor's characteristic traits. Factor analysis reveals the two-dimensional structure of the questionnaire items 'organ integration' (factor I) and 'relationship to the donor' (factor 2). Poor organ integration predicts low adherence, low disclosure and high feelings of guilt, whilst a close donor relationship predicts chronic stress and psychological distress.

Conclusions. Poor organ integration and a close relationship to the donor should be borne in mind in psychosocial treatment regarding the patient's adherence behaviour and psychological distress.

* Correspondence should be addressed to Dr Lutz Goetzmann, MD, Psychosocial Medicine, University Hospital Zurich, 809 I Zurich, Switzerland (e-mail: lutz.goetzmann@usz.ch). 


\section{CORRECTED PROOF}

\section{Copyright $\odot$ The British Psychological Society}

Reproduction in any form (including the internet) is prohibited without prior permission from the Society

\section{Lutz Goetzmann et al.}

In transplantation medicine, there is a growing body of literature dealing with both psychological and physical determinants of quality-of-life and psychological well-being before and after organ transplantation (for lung recipients, Cohen, Littlefield, Kelly, Maurer, \& Abbey, 1998; Goetzmann et al., 2005; Limbos, Joyce, Chan, \& Kesten, 2000; Littlefield et al., 1996; TenVergert et al., 1998). According to this research, both quality-of-life and psychological well-being improve significantly after transplantation. Nevertheless, very little is known about the psychological processes associated with transplantation.

Dating back to the 1970 s, there is some literature on how kidney patients deal with caring for a foreign organ. Muslin $(1971,1972)$ postulated a gradual internalisation of the transplanted organ. In the first stage of this integration, the transplant is perceived as a foreign object. In the next stage, the transplant represents both a 'foreign' and an 'own' object for the recipient. Only when internalisation is wholly complete is the transplanted organ perceived as a part of the patient's self. In Muslin's view, the representation of the donor (i.e. the way the recipient sees the donor) after the transplant is identical to the recipient's self-representation. Subsequently, the 'donor' representation detaches itself from the 'self' representation, roaming from the centre of the recipient's self into the external world. Lefebvre, Combez, and LeBeuf (1973) agreed with this conception, whilst other authors stressed individual variability and fluidity in the mental integration of the organ (Basch, 1973; Castelnuovo-Tedesco, 1973). Today, organ integration is one of the most important issues for transplant patients, and the achievement of a positive body image and integration of the new organ correlates with psychosocial well-being (Balck, 2008).

In a qualitative study of our own, we also encountered differences in organ integration (Goetzmann, 2004; Goetzmann et al., 2007). Furthermore, some patients reported a degree of identification with the donor, believing themselves to have adopted the donor's characteristic traits. In this study, there have also been indications of a correlation between poor organ integration or a close donor relationship on the one hand, and non-adherence behaviour ${ }^{1}$ on the other. Based on this qualitative research, we developed five questionnaire items in order to operationalise the concept of organ integration and the relationship to the donor.

Our first bypothesis was that most patients perceive the transplanted organ as a part of themselves, and that a very close relationship to the donor, including an adoption of personal traits, is only a minor problem after lung transplantation. The second bypothesis was based on the assumption that both organ integration and the relationship to the donor represent basic mental processes having an impact on symptoms such as chronic stress, distress, and health behaviour (e.g. adherence). We therefore expected patients with poor organ integration or those with a very close relationship to the donor to experience greater stress, distress, or feelings of guilt, and more problems in terms of adherence behaviour. The third bypothesis was that both organ integration and donor relationship are predominantly based on mental processes, and that they will have no significant correlations with the patient's physical health.

The questions posed by the study are as follows:

(1) How frequent are problems of psychological processing with regard to organ integration, and what role is played by the relationship with the donor?

\footnotetext{
'Adherence is defined as 'the extent to which patients follow the instructions they are given for prescribed treatment' (Haynes, Ackloo, Sahota, Mc Donald, \& Yao, 2008). In this article, adherence is related to the patient's immunosuppressive medication.
} 


\title{
CORRECTED PROOF
}

\section{Copyright $\odot$ The British Psychological Society}

Reproduction in any form (including the internet) is prohibited without prior permission from the Society

Psychological Processing of Transplantation in Lung Recipients

(2) Are transplant-related parameters reflecting organ integration and patient's relationship to the donor predictors for stress or psychological distress and adherence-behaviour? Are there physical or socio-demographic predictors (such as chronic rejection reaction or patient's age)?

(3) Is there a correlation between organ integration or the relationship to the donor on the one hand, and the patient's physical health status on the other?

\begin{abstract}
Methods
Sample and procedure

All patients who have undergone a lung transplant at the University Hospital Zurich with a time-gap of 3 months or more between surgery and assessment, an age above 16 years, and sufficient knowledge of the German language were asked to participate in this study. After approval by the Ethics Committee of the University Hospital Zurich, the study was announced by an informative letter to the 96 lung recipients in our programme who met these inclusion criteria. In the next step, the questionnaire was handed out to patients interested in taking part at their subsequent regular posttransplant check-up. In addition, patients signed an informed consent. Seventy-six patients $(77 \%)$ agreed to participate in the study, completing the questionnaire on the same day.
\end{abstract}

\section{Instruments}

The questionnaire included demographics such as age, gender and employment. Five items were adopted from a previous qualitative study of lung recipients (Goetzmann et al., 2007). These statements were an operationalisation of two concepts: one that the transplanted organ might be a 'foreign part' of the person in the first stage of integration, and a 'part of the self' in a later, more mature stage of integration, and that this development may be interrupted (for example by psychological conflicts or physical complications); and two, that the patient, experiencing a close relationship to the donor, is mentally preoccupied with the donor, and may believe that he has adopted some of the latter's character traits. We added the dimension 'current perceived importance of transplant events' to assess how intensely patients were currently preoccupied with the earlier transplant. The questions were answered by means of a 5-point Likert Scale (1, totally incorrect; 2, not correct; 3, unsure whether the statement is correct or not; 4 , correct; and 5, totally correct). The questionnaire items concerning organ integration are 'I perceive the graft as a foreign object in myself' (organ as foreign object) and 'The transplanted lung became a part of myself' (organ as part of the self). The items regarding the relationship to the donor are 'I often think of the donor' (thoughts of the donor) and 'Sometimes I have the impression that I have adopted some of the donor's traits' (adoption of donor's traits). The item 'The events accompanying transplantation don't matter to me today' relate to the current perceived importance of transplant events.

In addition, the following validated questionnaires were used to assess patients' chronic stress and psychological distress, as well as the emotional effects of the transplant and immunosuppression.

The 12-item Screening Scale of the Trier Inventory for the Assessment of Chronic Stress (TICS-SSCS) (Schulz, Scholtz, \& Becker, 2004) measures patients' chronic overall stress on a 5-point Likert scale ranging from 0 (never) to 4 (very often). It contains 


\section{CORRECTED PROOF}

\section{Copyright $\odot$ The British Psychological Society}

Reproduction in any form (including the internet) is prohibited without prior permission from the Society

\section{Lutz Goetzmann et al.}

12 items of the 57-item TICS, yielding the following dimensions of chronic stress: chronic worry, overwork, excessive demands at work, excessive social stress, and lack of social recognition.

The Symptom Checklist SCL-K-9 (Klaghofer \& Brähler, 2001) is a short version of the Symptom Checklist SCL-R (Derogatis, 1977). The SCL-90-R measures psychological distress and psychopathological symptoms in terms of hostility, obsessive-compulsive symptoms, depression, interpersonal sensitivity, paranoid ideation, anxiety, somatisation, phobic anxiety, and psychotic ideation. The German short version of SCL-K-9 is rated on a 5-point Likert scale between 0 (not at all) and 4 (very much), and is computed with nine items showing the highest correlation with the Global Severity Index (GSI-90), a summary of the SCL-R-90 designed to assess overall psychological distress over the last seven days. The SCL-K-9 has a one-dimensional factor structure, a Cronbach's $\alpha=.87$, and a mean value comparable to the GSI-90.

The Transplant Effects Questionnaire (TxEQ-D) measures the emotional response to organ transplantation with five subscales: patient's worry about the transplant, Feelings of guilt towards the donor, disclosure of transplant, self-reported adherence, and responsibility related to the functioning of the new organ (Ziegelmann et al., 2002; Griva et al., 2002). The five scales of the validated German version TxEQ-D show an internal consistency (Cronbach's alpha) of between 0.71 (Disclosure) and 0.79 (Adherence) (Klaghofer et al., 2008).

The Medication Experience Scale for Immunosuppressants (MESI) is a short screening instrument recording the subjective experiences and cognitive attitudes of patients vis-à-vis their immunosuppressive medication (Goetzmann, Klaghofer, Spindler et al., 2006; Goetzmann, Klaghofer, Wagner-Huber, et al., 2006). The scale shows an internal consistency (Cronbach's alpha) of 0.78 and a theoretical range of 4-33, with higher values indicating more negative experiences and attitudes.

\section{Physical parameters}

The forced expiratory volume in one second (FEV1) served as a measure of pulmonary function. Spirometry was performed with a mass flow-meter (66200 Autobox ${ }^{\circledR}$, Sensor Medics, Yorba Linda, CA). Criteria for acceptability, reproducibility and predicted normal values were according to the European Community of Coal and Steel ECCS (Quanjer et al., 1993). In addition, the diagnosis of the underlying disease leading to the lung transplant, the date of surgery, and current diagnosis of bronchiolitis obliterans syndrome (BOS) were recorded. The term 'chronic rejection' was used to describe the BOS according to the criteria of the International Society of Heart and Lung Transplantation (Estenne et al., 2002).

\section{Statistical analysis}

The statistical evaluation was carried out with SPSS 15.0 for Windows. Descriptivestatistics data were expressed in absolute numbers, per cent, means, and standard deviation (SD). The factor analysis of the items concerning the current perceived importance of transplant events, organ integration and the relationship to the donor was performed using principal component analysis, followed by an oblique rotation (Direct Oblimin) with Kaiser normalisation. The items 2 and 4 were reversed in Table 4 . The prediction of chronic stress (TICS-SCSS) and psychological distress (SCL-K-9) as well as the effects of transplantation (TxEQ-D) and immunosuppression (MESI) were 


\section{CORRECTED PROOF}

\section{Copyright $\odot$ The British Psychological Society}

Reproduction in any form (including the internet) is prohibited without prior permission from the Society

Psychological Processing of Transplantation in Lung Recipients

5

investigated by multiple regression analyses (method: enter); beta weights and adjusted $R^{2}$ values are presented.

\section{Results}

\section{Sociodemographic data and diagnoses}

Seventy-six of the 96 patients took part in this survey, yielding a response rate of $77 \%$. Table 1 shows the socio-demographic data and diagnoses of the underlying lung diseases.

Table I. Sociodemographic data and diagnoses $(n=76)$

\begin{tabular}{lclc}
\hline \multicolumn{2}{c}{ Sociodemographic data } & \multicolumn{2}{c}{ Diagnoses } \\
\hline $\begin{array}{l}\text { Sex } \\
\quad \text { Female }\end{array}$ & $33(44 \%)$ & Cystic fibrosis & $30(40 \%)$ \\
$\quad$ Male & $43(56 \%)$ & Chronic obstructive pulmonary disease & $26(34 \%)$ \\
$\begin{array}{l}\text { Age (years) } \\
M \text { (range), SD }\end{array}$ & $48.3(18-68), 14.7$ & & $14(18 \%)$ \\
$\begin{array}{l}\text { Time (months) since } \\
\text { transplantation }\end{array}$ & $48(3-133), 35.0$ & Pulmonary fibrosis & $3(4 \%)$ \\
$\begin{array}{l}M \text { (range), SD } \\
\text { Employment }>50 \%\end{array}$ & $8(10.5 \%)$ & Other lung diseases & \\
Employment $<50 \%$ & $50(65.8 \%)$ & & $3(4 \%)$ \\
\hline
\end{tabular}

As Table 1 shows, the sample comprised more men (56\%) than women (44\%). The mean age of respondents was 48.3 years $(S D=14.7)$. On average, the lung transplant had taken place 48 months previously, with a range of $3-133$ months and a right-skewed distribution. The largest diagnostic group consisted of patients with cystic fibrosis, followed by those suffering from chronic obstructive pulmonary disease.

\footnotetext{
Means and standard deviations of chronic stress, psychological distress, the effects of transplantation and immunosuppression

Table 2 shows means, SD and ranges of chronic stress (TICS-SSCS), psychological distress (SCL-K-9), effects of transplantation (TxEQ-D) and immunosuppression (MESI).

The mean value of chronic stress is 0.5 standard deviation below the norm (Schulz et al., 2004), and the mean value of psychological stress is 0.5 standard deviation above the norm (Klaghofer \& Brähler, 2001).
}

\section{Means and frequencies of the statements concerning the current perceived} importance of transplant events, organ integration and the relationship to the donor Table 3 shows the mean values and standard deviations of the statements relating the current perceived importance of transplant events, organ integration and the relationship to the donor.

The mean value of Statement 1 ('The transplanted lung became a part of myself') can be interpreted as indicative of good organ integration among these lung recipients. Patients' responses to Statement 2 ('I perceive the graft as a foreign object in myself') 


\section{CORRECTED PROOF}

\section{Copyright (C) The British Psychological Society}

Reproduction in any form (including the internet) is prohibited without prior permission from the Society

6 Lutz Goetzmann et al.

Table 2. Descriptive statistics of chronic stress (TICS-SSCS), psychological distress (SCL-K-9), effects of transplantation (TxEQ-D) and immunosuppression (MESI), $n=76$

\begin{tabular}{lrcc}
\hline Scale & Mean & SD & Range \\
\hline TICS-SSCS & 45.52 & 9.47 & $33-73$ \\
SCL-K-9 & 0.55 & 0.62 & $0.00-2.78$ \\
TxEQ-D worry about transplant & 2.30 & 0.66 & $1-4$ \\
TxEQ-D guilt & 1.56 & 0.63 & $1-4$ \\
TxEQ-D disclosure & 4.43 & 0.76 & $2-5$ \\
TxEQ-D adherence & 4.71 & 0.43 & $3-5$ \\
TxEQ-D responsibility & 3.06 & 1.00 & $1-5$ \\
MESI & 15.79 & 4.31 & $4-26$ \\
\hline
\end{tabular}

indicate that they do not experience the transplanted lung as a foreign object. The mean value of Statement 3 ('I often think of the donor') shows that patients are not normally very preoccupied with the donor. They do, however, report a degree of uncertainty as to whether the statement is correct or not. The mean value of Statement 4 ('The events accompanying transplantation don't matter to me today') shows that transplant events are currently perceived as important by almost half of the patients. Statement 5 emphasises the identification with the donor ('Sometimes I have the impression that I have adopted some of the donor's traits'). In our sample, patients' experience of having adopted certain traits of the donor is very slight.

Even though nearly half of the patients report that the events around the transplant still matter to them today, most of them claim to perceive the transplanted lung not as a foreign object, but as a part of themselves. Despite this, one-third still frequently think about the donor. Although the majority do not believe that they have adopted any of the donor's personal traits, almost $20 \%$ are either unsure of this, or actually report believing that this may be the case.

\section{Results of the factor analysis concerning the current perceived importance of transplant events, organ integration and relationship to the donor}

The factor analysis revealed two factors with an eigenvalue greater than 1 which explain $61 \%$ of the variance and are intercorrelated $(r=.18)$. In addition, the scree-plot clearly indicates a solution with two factors. Items 1 and 2 constitute factor 1 ('organ integration'), and items 3, 4 and 5 constitute factor 2 ('relationship to the donor'). The factor structure coefficients and communalities are presented in Table 4.

\section{Prediction of chronic stress, psychological distress, and the emotional effects of transplantation/immunosuppression}

According to the assumption that both organ integration and donor relationship represent basic mental processes that may have an impact on chronic stress, psychological distress or the patient's health behaviour, we defined both organ integration and donor relationship as predictors for the dependent variables of chronic stress and distress, and the emotional/behavioural effects of the transplantation/immunosuppression. Furthermore, we included the parameter 'chronic rejection reaction' (BOS; as one of the most obvious physical complications after a lung transplant) and the socio-demographic parameter 'patient's age' as predictors in the multiple regression model. 


\section{CORRECTED PROOF}

\section{Copyright (C) The British Psychological Society}

Reproduction in any form (including the internet) is prohibited without prior permission from the Society

Psychological Processing of Transplantation in Lung Recipients 7

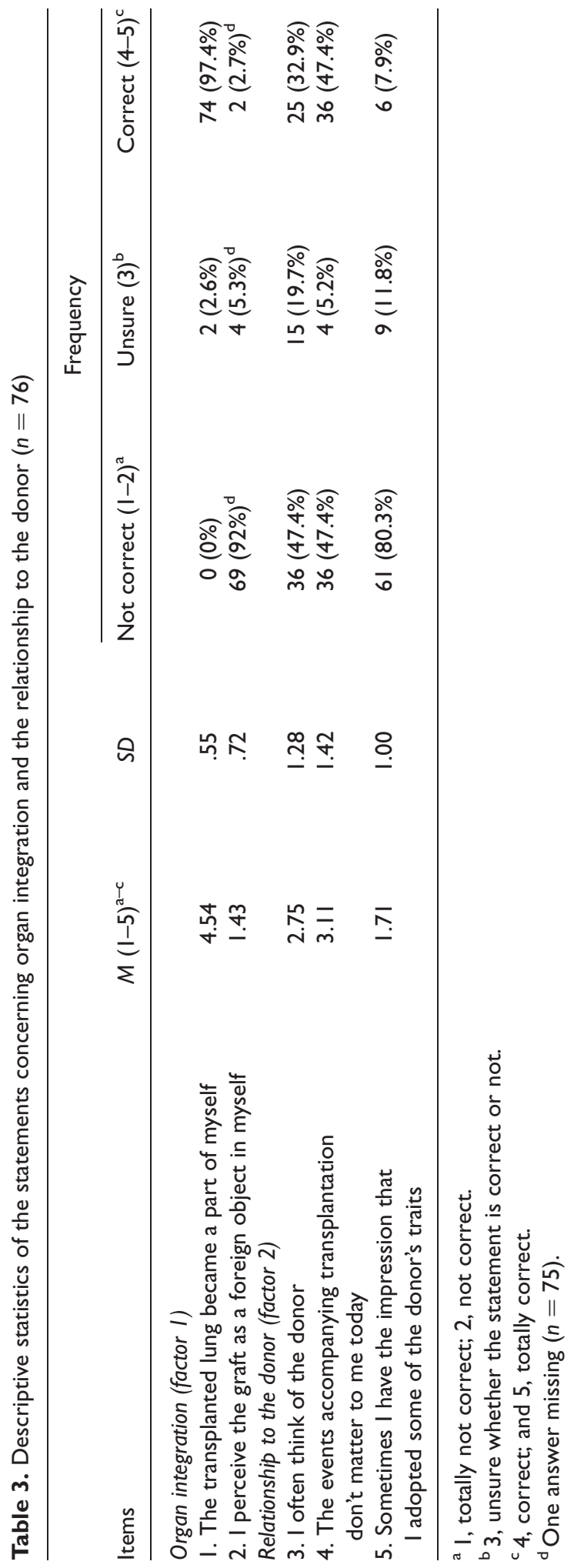




\section{CORRECTED PROOF}

\section{Copyright $\odot$ The British Psychological Society}

Reproduction in any form (including the internet) is prohibited without prior permission from the Society

8 Lutz Goetzmann et al.

Table 4. Results of factor analysis of the items concerning the current importance of transplant events, organ integration as well as the relationship to the donor $(n=76)$

\begin{tabular}{|c|c|c|c|}
\hline & \multicolumn{2}{|c|}{ Factor structure coefficients } & \multirow[b]{2}{*}{ Communality } \\
\hline & $\begin{array}{l}\text { Factor I } \\
\text { (organ } \\
\text { integration) }^{\mathrm{a}}\end{array}$ & $\begin{array}{l}\text { Factor } 2 \\
\text { (relationship to } \\
\text { the donor) }\end{array}$ & \\
\hline \multicolumn{4}{|l|}{ Items in factor I (organ integration) } \\
\hline I. The transplanted lung became a part of myself & .86 & -.07 & .73 \\
\hline $\begin{array}{l}\text { 2. I perceive the graft as a foreign object in myself } \\
\text { Items in factor } 2 \text { (relationship to the donor) }\end{array}$ & .85 & -.24 & .75 \\
\hline 3. I often think of the donor & -.05 & .79 & .63 \\
\hline $\begin{array}{l}\text { 4. The events accompanying transplantation } \\
\text { don't matter to me today }\end{array}$ & -.06 & .66 & .38 \\
\hline $\begin{array}{l}\text { 5. Sometimes I have the impression that I } \\
\text { adopted some of the donor's traits }\end{array}$ & -.39 & .62 & .51 \\
\hline
\end{tabular}

${ }^{\mathrm{a}}$ Factor I: eigenvalue $=1.83$, explained variance $=37 \%$

${ }^{\mathrm{b}}$ Factor 2: eigenvalue $=1.24$, explained variance $=24 \%$

Tables 5 and 6 show the results of the regression analysis for the two factors 'organ integration' and 'relationship to the donor' as well as BOS and age as predictors; chronic stress, psychological distress, and the emotional effects of the transplantation/immunosuppression are considered as the dependent variables.

As shown by Tables 5 and 6 , poor organ integration predicts guilt towards the donor (TxEQ-D), low disclosure (TxEQ-D), and low adherence (TxEQ-D). A close relationship to the donor is a predictor for chronic stress (TICS-SCSS), psychological distress (SCL-K-9), worry about the transplant (TxEQ-D), and feelings of guilt (TxEQ-D). The physical parameter $B O S$ is not a predictor for the dependent psychosocial variables. Age of patient predicts responsibility (TxEQ-D), with elderly people experiencing a greater sense of responsibility vis-à-vis the transplant.

Associations with physical health (FEVI, BOS diagnosis, time since transplantation) There is no significant correlation between the two dimensions 'organ integration'/'relationship to the donor' on the one hand, and current lung function (FEV1) or current occurrence of a chronic rejection reaction (BOS) on the other. Furthermore, there are no significant differences between patients with cystic fibrosis and those with another lung disease. Time since transplantation is not significantly correlated (Spearman's rho) with 'organ integration'/ 'relationship to the donor'.

\section{Discussion}

Seventy-six lung recipients were asked to comment on transplant integration and their imagined relationship with the donor. The main finding of the present quantitative study is that poor organ integration and the perceived adoption of the donor's imagined character traits - in the sense of a very closeness to the donor - are not typical transplant-related phenomena, which means that the majority of patients have considerable potential for adaptation. Nevertheless, a minority of patients are 


\section{CORRECTED PROOF}

\section{Copyright (C) The British Psychological Society}

Reproduction in any form (including the internet) is prohibited without prior permission from the Society

Psychological Processing of Transplantation in Lung Recipients 9

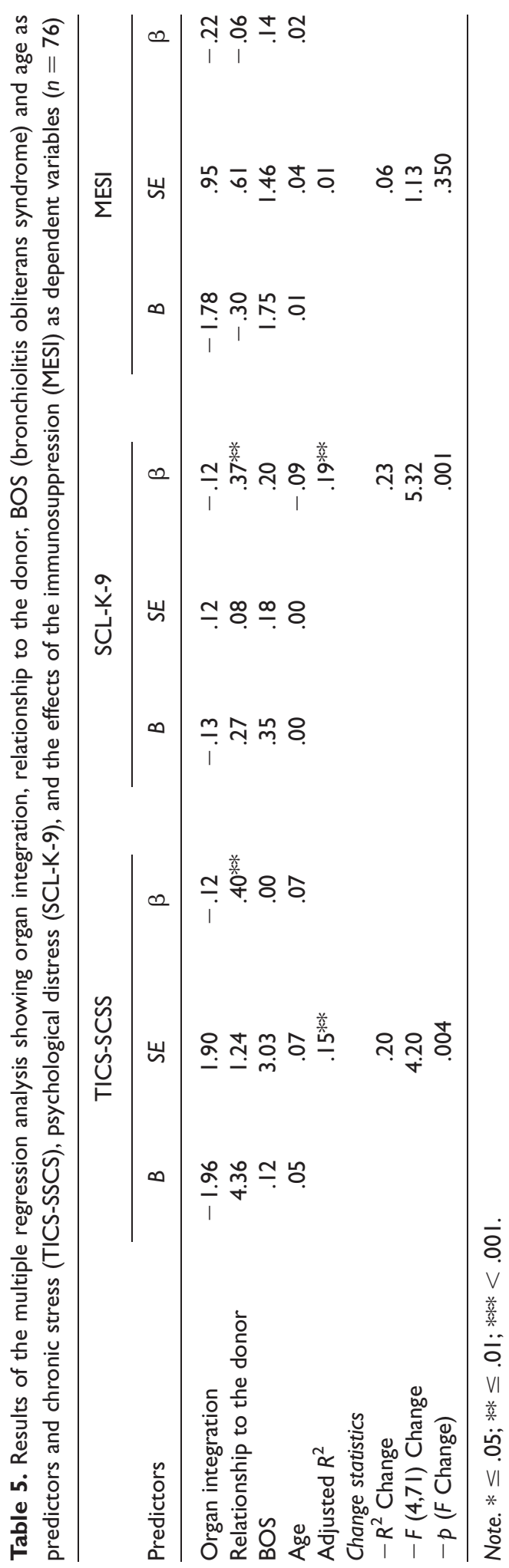




\section{CORRECTED PROOF}

\section{Copyright (C) The British Psychological Society}

Reproduction in any form (including the internet) is prohibited without prior permission from the Society

I0 Lutz Goetzmann et al.

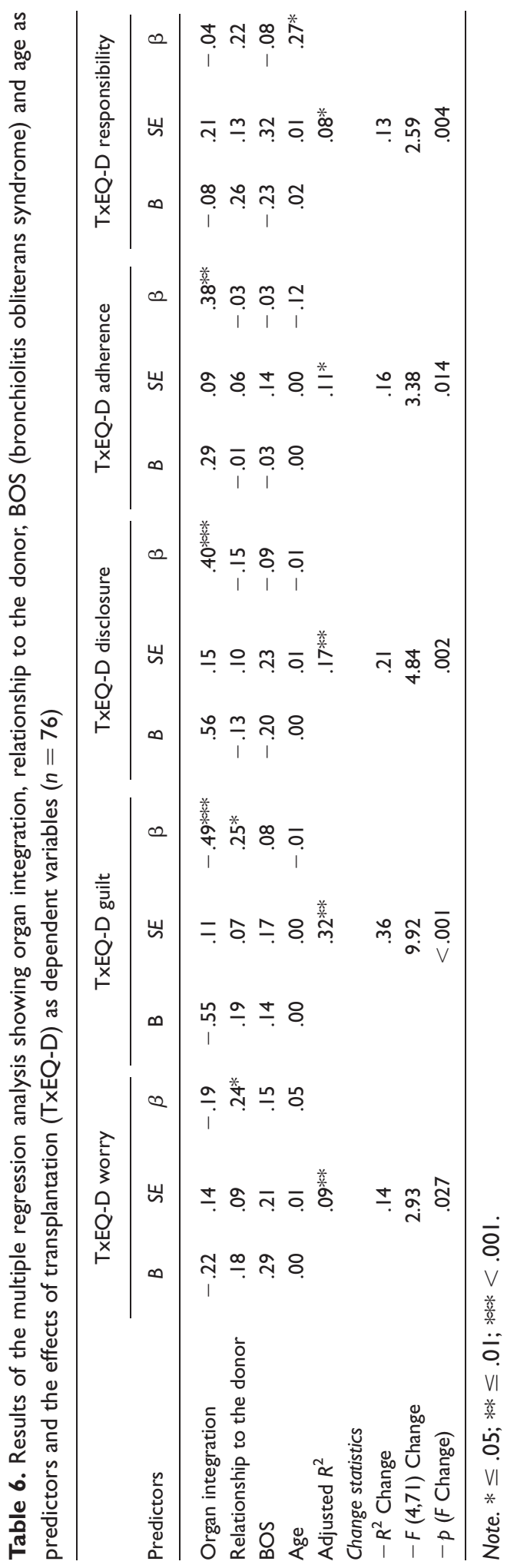




\section{CORRECTED PROOF}

\section{Copyright $\odot$ The British Psychological Society}

Reproduction in any form (including the internet) is prohibited without prior permission from the Society

concerned about such experiences, whose association with poor adherence or psychological distress underline the clinical importance of these findings.

\section{Current perceived importance of the transplant events, organ integration and the relationship to the donor: Mean values and frequencies}

In our survey, we first assessed the current importance ascribed by patients to transplant events. We learned that almost half of the patients still considered incidents relating to the transplant to matter in their current lives. This result was statistically independent of the amount of time elapsed since transplantation. It shows that transplantation as a lifeevent plays a sustained and important role in the life of lung recipients.

There is a high degree of organ integration among lung recipients at least 3 months after transplantation or later on. Generally, patients experience the transplanted organ as a part of themselves and not as a foreign body. In previous publications, Muslin (1971, 1972) and other authors (Lefebvre et al. 1973) describe organ integration as a long-term, step-by-step process. This process may be interrupted by emotional difficulties of any kind, causing the transplanted organ to remain a foreign, possibly hostile object in the patient's body as well as in his or her representational world. However, poor organ integration appears only in a minority of patients.

In our survey, the patients were also asked to comment on their attitudes towards the donor: firstly, whether they often think of the donor, and secondly, whether they have internalised some of the donor's imagined characteristics. One-third of patients (32.9\%) still think about the donor frequently, and almost $20 \%$ are either not sure whether they have adopted some of the donor's characteristics (11.2\%), or actually report having acquired some of the latter's traits $(7.9 \%)$. We interpret this process in terms of an identification: the idea of having incorporated the donor's personality traits, e.g. his laughter, as one patient in the previous interview study stated (Goetzmann et al., 2007), may be the result of the projection of one's own attributes on to the representation of the donor.

\section{Results of the factor analysis concerning the current perceived importance of transplant events, organ integration and the relationship to the donor}

The factor analysis revealed a two-dimensional structure of the questionnaire items. Factor 1 consists of the items that the lung is a part of the patient or the lung is a foreign object. Factor 2 consists of the items that the patient often thinks of the donor, or has adopted some of the donor's traits. The current perceived importance of the transplant events also forms part of factor 2.That this item is part of the factor 'relationship to the donor' underscores the very important role played by the donor in the patient's emotional processing of the transplant. Persistent thoughts about the donor may the cause patients to remain attached to earlier transplant events. Furthermore, the twodimensional structure shows that the statements fit quite well into the psychodynamic construct of organ integration/donor relationship, forming a short questionnaire on these clinically important topics.

\section{Prediction of chronic stress, psychological distress and the emotional effects of transplantation/immunosuppression}

In the multiple regression model, we tested whether organ integration and the relationship to donor predict chronic stress, psychological distress or the emotional 


\section{CORRECTED PROOF}

\section{Copyright $\odot$ The British Psychological Society}

Reproduction in any form (including the internet) is prohibited without prior permission from the Society

\section{Lutz Goetzmann et al.}

effects of the transplant/immunosuppression. Furthermore, we integrated physical and socio-demographic parameters (BOS, age) into the model. We assumed that psychological questions regarding the incorporation of the organ into the patient's world as well as questions of an intense closeness to the donor represent basic mental processes that may influence the degree of symptoms such as stress, distress, feelings of guilt, or the patient's health behaviour, i.e. adherence. The results show that patients reporting problems with organ integration are primarily affected by feelings of guilt. It appears to be difficult to accept an organ psychologically whilst feeling guilty towards the donor. Poor organ integration is also predictive of low disclosure, in other words, patients avoid revealing themselves as transplant recipients. These patients report particular difficulties in terms of adherence behaviour. The rate of immunosuppressant non-adherence stands at about $23 \%$ among transplant patients, making it one of the most important issues in transplantation medicine (Dew et al., 2007). Thus, to prevent nonadherence, the process of organ integration should be carefully addressed by the treating physicians. Patients with signs of a very close relationship to the donor report more stress, distress, guilt and worries. Thus, patients who are able to integrate their new organ report better adherence, and those who build an aloof, separate relationship with the donor report less stress or distress.

Because a chronic rejection reaction (BOS) is not a predictor of stress/distress or the other psychosocial parameters, we might postulate that psychosocial strains tend to be caused by poor organ integration or a close relationship to the donor, and only to a lesser extent, if at all, by the current physical status of the transplanted organ. Moreover, patient's age predicts sense of responsibility only: elderly patients clearly feel more responsible towards their new organ.

\section{Associations of organ integration and the relationship to the donor with physical health, age and time since transplantation}

Because we have found no significant correlations between physical health on the one hand and organ integration/donor relationship on the other, integrating a transplant and sorting out one's relationship with the donor would appear to be a psychological process that is not influenced, or at least not directly influenced, by the current physical status of the transplanted organ. Remarkably, we found that neither the age of the patient nor the time elapsed between the surgery and the post-transplant assessment influenced the outcomes in terms of organ integration and the quality of donor relationship. It would therefore appear that both the psychological integration of the organ and the donor/recipient relationship are organised and more or less definitively shaped during the first few months after transplantation. Furthermore, for some people the process of adaptation and integration may start before the transplant, as patients prepare themselves for the procedure.

Addressing the limitations of the study, the cross-sectional design should be considered first. Thus, there are no definitive causal connections between the different possible psychosocial parameters. Longitudinal studies are needed in this area. Furthermore, the statements concerning the perception of both the organ and the donor do not currently meet the statistical criteria of a validated questionnaire, and it is only a very brief measure with two or three items per section. Because of this limitation, the data of the study have to be interpreted with some caution. However, one interesting result may be that qualitative findings - chiefly, that poor organ integration is associated with non-adherence - have now been confirmed by quantitative means. 


\section{CORRECTED PROOF}

\section{Copyright (C) The British Psychological Society}

Reproduction in any form (including the internet) is prohibited without prior permission from the Society

\section{Conclusions}

Problems with organ integration and donor relationship only affect a minority of lung recipients. It is important for health professionals to know that these problems are quite rare, but that when they occur, they are usually in association with psychological distress, feelings of guilt and shame, and above all, poor adherence, which underscores their clinical relevance. There is a need to be able to identify individual differences between patients in processing a lung transplant, as well as to be able to predict a subgroup of patients who will be likely to suffer from psychosocial stress and problems including non-adherence behaviour. The aim of future research on this topic should be to develop tools for measuring organ integration and perception of the donor that meet the conditions of a validated questionnaire.

\section{References}

Balck, F. (2008). Transplantationsmedizin, psychosoziale Aspekte [Transplantation medicine, psychosocial aspects]. In H. Berth, F. Balck, \& E. Brähler (Eds.), Medizinische Psychologie und Medizinische Soziologie von A bis $Z$ (pp. 489-499). Göttingen: Hogrefe.

Basch, S. H. (1973). The intrapsychic integration of a new organ: A clinical study of kidney transplantation. Psychoanalytic Quarterly, 42, 364-384.

Castelnuovo-Tedesco, P. (1973). Organ transplant, body image, psychosis. Psychoanalytic Quarterly, 42, 349-363.

Cohen, L., Littlefield, C., Kelly, P., Maurer, J., \& Abbey, S. (1998). Predictors of quality of life and adjustment after lung transplantation. Chest, 113, 633-644.

Derogatis, L. R. (1977). SCL-90-R: Administration, scoring, and procedures manual-i for the r(evised) version. Baltimore, MD: John Hopkins University School of Medicine.

Dew, M. A., DiMartini, A. F., De Vito Dabbs, A., Myaskovsky, L., Steel, J. L., Unruh, M., et al. (2007). Rates and risk factors for nonadherence to the medical regimen after adult solid organ transplantation. Transplantation, 83, 853-878.

Estenne, M., Maurer, J. R., Boehler, A., Egan, J. J., Frost, A., Hertz, M., et al. (2002). Bronchiolitis obliterans syndrome 2001: An update of the diagnostic criteria. Journal of Heart and Lung Transplantation, 21, 297-310.

Goetzmann, L. (2004). 'Is it me, or isn't it?' - transplanted organs and their donors as transitional objects. American Journal of Psychoanalysis, 3, 279-289.

Goetzmann, L., Klaghofer, R., Spindler, A., Wagner-Huber, R., Scheuer, E., \& Buddeberg, C. (2006). Die "Medikamentenwirkung-Erfahrungs-Skala für Immunsuppressiva" (MESI) - ein neues 7-item Screening Instrument in der Transplantationsmedizin [The "Medication Experience Scale for Immunosuppressants" (MESI): Initial results for a new screening instruments in transplant medicine]. Psychotherapie, Psychosomatik, Medizinische Psychologie, 56, 49-55.

Goetzmann, L., Klaghofer, R., Wagner-Huber, R., Halter, J., Boehler, A., Muellhaupt, B., et al. (2006). Quality of life and psychosocial situation before and after a lung, liver or an allogeneic bone marrow transplant - results from a prospective study. Swiss Medical Weekly, 136, 281-290.

Goetzmann, L., Moser, K. S., Vetsch, E., Naef, R., Russi, E. W., Buddeberg, C., et al. (2007). How does psychological processing relate to compliance behaviour after lung transplantation? $A$ content analytical study. Psychology Health Medicine, 12, 94-106.

Goetzmann, L., Scheuer, E., Naef, R., Vetsch, E., Buddeberg, C., Russi, E. W., et al. (2005). Psychosocial situation and physical health in 50 patients more than one year after lung transplantation. Chest, 127, 166-170.

Griva, K., Ziegelmann, J. P., Thompson, D., Jayasena, D., Davenport, A., Harrison, M., et al. (2002). Quality of life and emotional responses in cadaver and living related renal transplant recipients. Nephrology Dialysis Transplantation, 17, 2204-2211. 


\section{CORRECTED PROOF}

\section{Copyright $\odot$ The British Psychological Society}

Reproduction in any form (including the internet) is prohibited without prior permission from the Society

I4 Lutz Goetzmann et al.

Haynes, R. B., Ackloo, E., Sahota, N., McDonald, H. P., \& Yao, X. (2008). Interventions for enhancing medication adherence (review). The Cochrane Collaboration. New York, NY: Wiley.

Klaghofer, R., \& Brähler, E. (2001). Konstruktion und teststatistische Prüfung einer Kurzform der SCL-90-R. Zeitschrift für Psychosomatische Medizin und Psychotherapie, 49, 115-124.

Klaghofer, R., Sarac, N., Schwegler, K., Schleuniger, M., Noll, G., Muellhaupt, B., et al. (2008). Fragebogen zur psychischen Verarbeitung einer Organtransplantation: Deutsche Validierung des Transplant Effects Questionnaire (TxEQ) [Questionnaire for emotional response after organ transplantation: German validation of the Transplant Effect Questionnaire (TxEQ-D)]. Zeitschrift für Psychosomatische Medizin und Psychotherapie, 2 (pp. 144-188).

Lefebvre, P., Combez, J. C., \& LeBeuf, J. (1973). Psychological dimension and psychopathological potential of acquiring a kidney. Canadian Psychiatric Association Journal, 18, 495-500.

Limbos, M. M., Joyce, D. P., Chan, C. K., \& Kesten, S. (2000). Psychological functioning and quality of life in lung transplant candidates and recipients. Chest, 118, 408-416.

Littlefield, C., Abbey, S., Fiducia, D., Cardella, C., Greig, P., Levy, G., et al. (1996). Quality of life following transplantation of the heart, liver, and lungs. General Hospital Psychiatry, 18, 36-47.

Muslin, H. L. (1971). On acquiring a kidney. American Journal of Psychiatry, 127, 105-108.

Muslin, H. L. (1972). The emotional response to the kidney transplant: The process of internalization. Canadian Psychiatric Association Journal, 17, 3-8.

Quanjer, P., Tammeling, G. J., Cotes, J. E., Pedersen, O. F., Peslin, R., \& Yernault, J. C. (1993). Lung volumes and forced ventilatory flows. European Respiratory Journal, 16, 5-40.

Schulz, P., Scholtz, W., \& Becker, P. (2004). Trier inventory for the assessment of chronic stress. Goettingen: Hogrefe, (in German).

TenVergert, E. M., Essink-Bot, M. L., Geertsma, A., van Enckevort, P. J., de Boer, W. J., \& van der Bij, W. (1998). The effect of lung transplantation on health-related quality of life. Chest, $113,358-364$.

Ziegelmann, J. P., Griva, K., Hankins, M., Harrison, M., Davenport, A., Thompson, D., et al. (2002). The Transplant Effects Questionnaire (TxEQ). The development of a questionnaire for assessing the multidimensional outcome of organ transplantation - example of end stage renal disease (ESRD). British Journal of Health Psychology, 7, 393-408.

Received 5 May 2008; revised version received 26 November 2008 